\title{
The Bussola Study. Final Results, Conclusions and Proposals
}

\author{
Antonio Luiz da Silva Brasileiro (on beharff of the study partipants)
}

Rio de Janeiro, RJ - Brazil

\begin{abstract}
Objective - To evaluate the use of thrombolytic and acetylsalicylic acid therapies in acute myocardial infarct patients as well as the availability of technical and human resources for the care of these patients in the emergency units of the city of Rio de Janeiro. Additional objectives were the evaluation of the use of primary angioplasty and the level of acceptance of SBC/RJ as an entity responsible for programs of continued medical education.
\end{abstract}

Methods - Interviews with physicians at 46 emergency units in the city of Rio de Janeiro.

Results - Of the 46 emergency units inspected, a policy of encouragement to use thrombolytic therapy was only prescribed in $6.5 \%$. In 1/3 of the public wards no thrombolytic agents were available, and in none of them was access to primary angioplasty regularly available; $45.9 \%$ did not offer the minimal conditions required for the handling of cases of acute myocardial infarction; $60 \%$ of the physicians on-call (at both public and private emergency units), appeared not to know the importance of the use of acetylsalicylic acid in acute myocardial infarct patients; all physicians interviewed would participate in programs of continued medical education organized by the SBC/RJ.

Conclusion - The study suggests there was: 1) the low probability of the use of thrombolytic therapy in the majority of the emergency units in of the city of Rio de Janeiro due to the inadequate policy of waiting for the transfer of the patient to coronary or intensive care unit; 2) a low awareness to the importance of early use of acetylsalic acid in acute myocardial infarct; 3) half of the emergency units of the public net do not have the minimal conditions required for the handling of cases of acute myocardial infarction; 4) a high level of credibility exists that would enable the SBC/RJ to set up programs for continued medical education to change the mentality regarding the use of thrombolytic therapy and of acetylsalicylic acid.

Keywords: myocardial infarct, thrombolysis, emergencies

Universidade do Estado do Rio de Janeiro - UERJ

Mailing address: Antonio L. da Silva Brasileiro - Av. Marechal Henrique Lott 270/107 - 22631-370 - Rio de Janeiro, RJ - Brazil - E-mail: abrasil@rio.com.br
Ever since the advent of coronary units in $1962^{1}$, no other fact has left a stronger impression on the cardiology community than the publication in 1986 of the GISSI study ${ }^{2}$, demonstrating a reduction in acute myocardial infarct mortality of up to $47 \%$ and contributing to the division of this specialty into pre- and postthrombolytic therapy eras.

"Time is muscle" became the new paradigm. Since then, all efforts have been directed towards increased awareness by physicians in emergency units of the necessity for rapid transfer of acute myocardial infarct patients to a coronary unit for initiation of thrombolytic therapy. This initial strategy, based on the prudance to a new drug, soon showed itself to be inadequate, because the drug's time-dependent benefits were delayed until after the patient's arrival at the coronary unit or center for intensive therapy. This amounted in many instances to denying the patient his or her main chance for survival. It was furthermore found that its excellent risk/benefit ratio eliminated the need for an intensive therapy environment for the drug's prescription. Thus, a new challenge set in: to make physicians aware of the importance of the initiation of thrombolytic therapy in the emergency unit itself ${ }^{3-10}$, so the decisive place for the acute myocardial infarct patient moved from the coronary unit to the emergency unit. All over the world, campaigns aimed at stimulating the use of thrombolytic therapy as precociously as possible have been initiated. The bestknown program, the National Heart Attack Alert Program (NHAAP) coordinated by the National Heart, Lung and Blood Institute in the United States of America, was launched in $1991{ }^{10}$ with the participation of 39 organizations including the major medical societies of that country. It was however recommended by NHAAP that campaigns fostering awareness in the population (to look for hospitalization as rapidly as possible) should only be started following adequate training and awareness of the physicians who would be rendering the first assistance to these patients.

As far as we know, up to the present, no program with such objective exists in Brazil. Therefore, at this time, the place for thrombolytic therapy remains the coronary unit. We may cite as an example the case of the Laranjeiras Cardiology Hospital, an important public cardiology referral center in the State of Rio de Janeiro where in a survey made 
between 1989 and 1997, we observed that the majority of their acute myocardial infarct inpatients had not received thrombolytic therapy at the emergency units. As these patients usually arrived very late to the coronary unit, the use of the drug had frequently become inadequate (fig. 1). We also noted that $95.6 \%$ of these patients arrived at the place where they received their initial attention within $12 \mathrm{~h}^{11}$. A study by Xavier et al ${ }^{12}$ showed that patients hospitalized for acute myocardial infarction at the Clementino Fraga Hospital of the University of Rio de Janeiro also did not receive thrombolytic therapy at the emergency units where they went for medical help in spite of frequently being within first $2 \mathrm{~h}$ of symptoms. Some epidemiological studies ${ }^{13-14}$ have shown a dramatic situation in Rio de Janeiro, which, in a survey from 1980 to 1997 , reveals itself to be the national leader in deaths by acute myocardial infarct (fig. 2). Such a situation will only be reversed by political will and a partnership between the Brazilian Society of Cardiology/Rio de Janeiro (SBC/RJ) and the Regional Council of Medicine of the State of Rio de Janeiro, aimed at the implementation of objective measures. Aiming at obtaining wider information about what is being offered to the bearers of acute myocardial infarction in the emergency units, the BÚSSOLA study (the

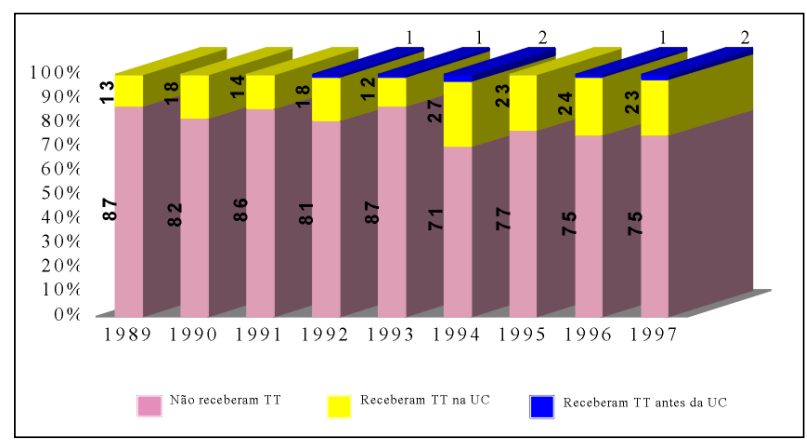

Fig. 1 - Relation between patients hospitalized at the Coronary Unit (CU) of the Cardiology Hospital of Laranjeiras for acute myocardial infarct between 1989 and 1997, distinguished by having or not received thrombolytic therapy (TT) and where received. The figure shows the low use, also after arrival, in general due to delayed removal.

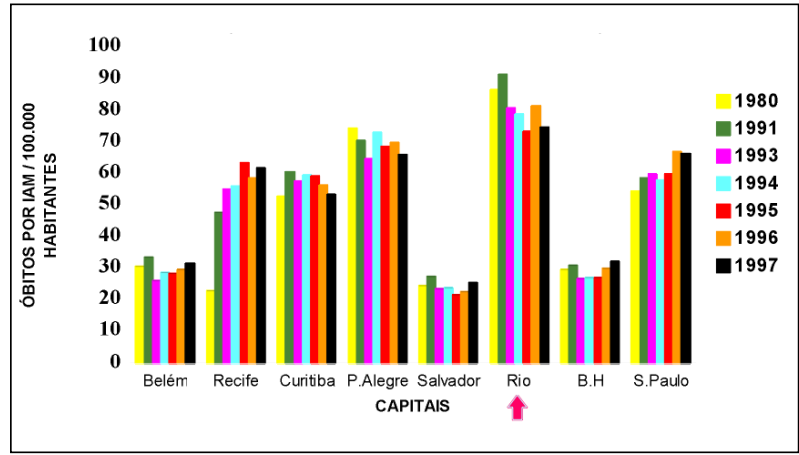

Fig. 2 - Acute myocardial infarct mortality index in the eight largest Brazilian state capitals evaluated in years when official data (demographic and mortality) were available. Note that Rio de Janeiro has the largest mortality index over all the years. Sources: Brazilian Institute of Geography and Statistics (IBGE) and Datasus (Ministry of Health/National Health Foundation).
The Bussola study. Final results, conclusions and proposals

portuguese word for compass) was conceived to look, with the support of the SBC/RJ, for solutions to the problem of the underuse of thrombolytic therapy in cardiology emergencies in the city of Rio de Janeiro.

The objectives of this study were: evaluate the probability that acute myocardial infarct patents would have precociously administered reperfusion therapy (thrombolytic or primary angioplasty) in emergency units in the city; to evaluate the quality of such attention; to evaluate the degree of use of acetylsalicylic acid as part of the treatment of the infarct; and to evaluate the acceptance of SBC/RJ as the promoter of a program for continuous medical education of health professionals active in emergency units.

\section{Methods}

A questionnaire predefined in a pilot study was used to interview the head physicians of 46 emergency units ( 24 public, 22 private) in the city of Rio de Janeiro. The choice of these units was based on information obtained from the Health Office of the Municipality of Rio de Janeiro concerning the number of cases attended in these emergency rooms. At least one on-call physician (randomly chosen from those in attendance at emergency units to treat patients suspected of having an acute myocardial infarction) was also interviewed. Interviews were made in April and May of 1998 by 21 participants ( 11 residents and 10 last year medical probationers) in the study, who had a letter of introduction signed by the President of the SBC/RJ and by the coordinator/author of the study.

The evaluation of the probability of the performance of some form of precocious reperfusion therapy (objective 1) was based on answers of the head physicians to the question: "Which is the general policy for the use of thrombolytic therapy in your emergency unit?". The following answers were given: a) we do not have the drug; b) we do not use it because we do not have an adequate setup for this; c) we do not use it because our physicians have not yet demonstrated an interest in this therapy; d) our policy is to

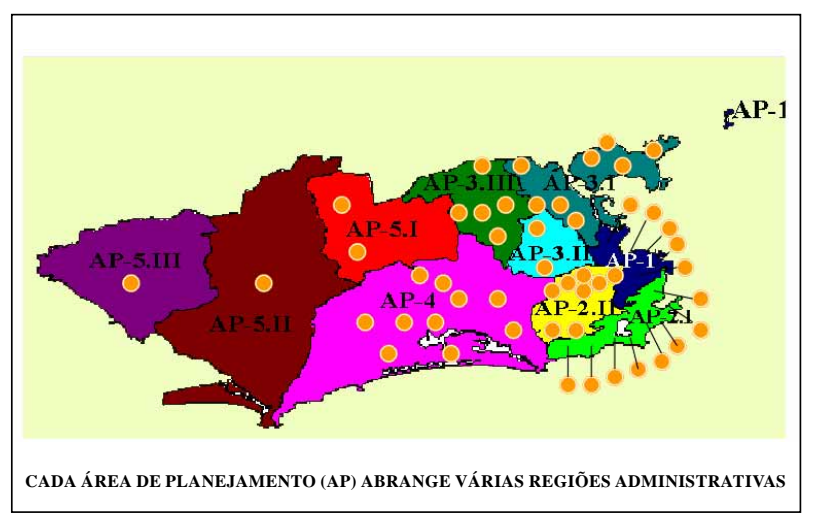

Fig. 3 - Geographical distribution of the emergencies studied. Map by the Health Municipality of Rio de Janeiro. Localization of the 46 emergency units visited. There exists a correspondence of these sites with demographic density. 
have the use of this drug initiated in the intensive therapy unit or the coronary unit; e) we have no policy; the decision is exclusively up to the physician on duty; f) we always perform primary angioplasty; $g$ ) we recommend that the use of the drug be initiated in the emergency unit itself when no rapid transportation to the coronary/intensive therapy unit is possible.

We felt that there would by a low probability for the performance of some form of reperfusion therapy in the emergency units if answers were a, b, c, or d; a moderate probability if the answer was e; and a high probability if it had been for $g$.

To evaluate the quality of the medical attention rendered (objective 2), we classified the emergency units into categories according to their available resources. Minimal conditions for treatment of patients with a picture of acute myocardial infarct would be: availability for use of an electrocardiograph, a defibrillator, and a thrombolytic agent; presence of a cardiologist on duty during the majority of the period, or the existence of an intensive therapy center. The availability for use of additional resources placed the emergency units in higher categories, ranging up to excellent. The following resources were taken into consideration: 1) a policy of the local head officials to provide a moderate to high probability for the performance of precocious thrombolytic reperfusion therapy (see criteria above); 2) the possession of at least seven of the following nine requisites: a cardiac monitor, possibility of measurement of CKMB, myoglobin, troponin, echocardiography, thoracic teleradiography, MA1 or a higher respirator, temporary pacemaker, a strategy of prioritization of attention to patients with thoracic pain; 3) a coronary unit; 4) the possibility of quick access to interventional procedures; 5) the possibility of a 24 $\mathrm{h}$ /day access to such interventions; 6) the possibility of emergent cardiac surgery; 7) the possibility of this access $24 \mathrm{~h} /$ day.

\section{Results}

Table I shows that, although lack of availability of thrombolytics was a problem in only $17.4 \%$ of the emergency units visited, the absence of an implementation policy on part of the head officials would probably impede the performance of a precocious reperfusion therapy in the majority of them. Only $6.5 \%$ of the head physicians adopted the presently advocated policy of initiation of thrombolytic therapy right at the emergency unit when quick transfer to a coronary or intensive therapy unit proved impossible.

Using criteria of high, moderate, or low probability, we verified that in only $12.5 \%$ of the public and in $27.3 \%$ of the private emergency units would patients with an acute myocardial infarct have a high probability of being given some form of precocious reperfusion therapy to obtain a significant reduction in the risk of death (table II).

Table III shows a numerical view of the situation, showing that $45.9 \%$ of the public emergency units did not offer even minimal conditions for such attention. Among the private institutions, only $4.5 \%$ did not meet such minimal conditions.

The answers to the question shown in table IV suggest that the majority of the professionals active in the emergency units did not have an adequate degree of awareness of the importance of the use of acetylsalicylic acid in a patient with acute myocardial infarction. This was observed both in public and private emergency units.

All 97 physicians interviewed answered favorably regarding the future presence of the SBC/RJ in their emergency units to promote programs of continued medical education (table V).

\section{Discussion}

The high level of cardiology practiced in many public and private centers of the city of Rio de Janeiro is well known. Yet, the high mortality rate due to acute myocardial infarct in this city ${ }^{13}$ seems to indicate that the greatest part of the population does not have access to this good quality of service, a fact that can be confirmed by some of the results found in this study, showing that nearly half of the public emergency units (which treat the largest part of the population) did not have even minimal conditions for managing acute myocardial infarct patients. Paradoxically, the

Table I - Interviews with head officials of emergency units: "What is the general policy for the use of thrombolytic therapy in this emergency unit?"

\begin{tabular}{|c|c|c|c|c|c|c|}
\hline \multirow[t]{2}{*}{ Answer options } & \multicolumn{2}{|c|}{$\begin{array}{l}\text { Total } \\
\text { units }\end{array}$} & \multicolumn{2}{|c|}{$\begin{array}{c}\text { Public } \\
\text { units }\end{array}$} & \multicolumn{2}{|c|}{$\begin{array}{c}\text { Private } \\
\text { units }\end{array}$} \\
\hline & № & $\%$ & № & $\%$ & № & $\%$ \\
\hline a) Drugs are not available & 8 & 17.4 & 8 & 33.4 & 0 & 0.0 \\
\hline b) Drugs are not used because we have no adequate structure & 3 & 6.5 & 2 & 8.3 & 1 & 4.5 \\
\hline $\begin{array}{l}\text { c) We do not use it because our physicians have not } \\
\text { shown an interest in this form of therapy }\end{array}$ & 0 & 0.0 & 0 & 0.0 & 0 & 0.0 \\
\hline $\begin{array}{l}\text { d) Our policy is to let use of this drug be initiated at } \\
\text { coronary/intensive care units }\end{array}$ & 14 & 30.5 & 4 & 16.6 & 10 & 45.4 \\
\hline e) There is no policy. The decision is exclusively up to the physician on duty & 12 & 26.1 & 7 & 29.2 & 5 & 22.8 \\
\hline f) We always perform primary angioplasty & 6 & 13.0 & 0 & 0.0 & 6 & 27.3 \\
\hline $\begin{array}{l}\text { g) We recommend the use of the drug be initiated at the emergency } \\
\text { unit itself whenever rapid transfer to the intensive } \\
\text { therapy/coronary units is not possible }\end{array}$ & 3 & 6.5 & 3 & 12.5 & 0 & 0.0 \\
\hline
\end{tabular}




\begin{tabular}{|lcccccc|}
\hline $\begin{array}{l}\text { Table II - Probability of reperfusion therapy to be administered in } \\
\text { cases of acute myocardial infarct in }\end{array}$ the emergency units studied \\
\hline Probability & $\begin{array}{l}\text { Total } \\
\text { units }\end{array}$ & \multicolumn{2}{c}{$\begin{array}{c}\text { Public } \\
\text { units }\end{array}$} & $\begin{array}{c}\text { Private } \\
\text { units }\end{array}$ \\
\hline & № & $\%$ & № & $\%$ & № & $\%$ \\
High & 9 & 19.5 & 3 & 12.5 & 6 & 27.3 \\
Moderate & 12 & 26.1 & 7 & 29.1 & 5 & 22.7 \\
Low & 25 & 54.4 & 14 & 58.4 & 11 & 50.0 \\
\hline
\end{tabular}

\begin{tabular}{|lcccccc|}
\hline \multicolumn{7}{|c|}{ Table III - Results regarding the quality of the care offered at the } \\
emergency units of Rio de Janeiro
\end{tabular}

best equipped public hospitals, for reasons justifiable or not, do not accept emergency cases. Thus, the population does not have access to an up to date form of medicine precisely at the moment of its greatest need. This occurs at University Hospitals Clementino Fraga and Pedro Ernesto and at the Cardiology Hospital of Laranjeiras (Health Ministry), the cardiology referral center for the State. Another important factor is the lack of clear and necessary positioning of the head officials of emergency units in favor of the use of a thrombolytic agent as soon as possible in the emergency unit, thus loosing an excellent opportunity to reduce the high mortality rates found. Furthermore, a lack of awareness is evident on the part of the physicians about the importance of the use of acetylsalicylic acid in acute myocardial infarction, as suggested by this study, which shows the deficiencies of all the main pillars sustaining the structure of emergency service in the city, be they authorities, head physicians, or physicians in attendance.

Based on the results found, we present initial, simple proposals that can be put into practice immediately (some already ongoing) by the SBC/RJ: 1) setting up a minimal protocol to perform thrombolytic therapy in emergencies; 2) promoting lectures at emergency units about the im-
The Bussola study. Final results, conclusions and proposals

portance and safety of the use of thrombolytic therapy (ongoing); 3 ) promoting a public awareness campaign about the importance of the use of aspirin in patients with suspected acute myocardial infarction; 4) increasing awareness of public health authorities about the need to supply all their emergency units with thrombolytic drugs as well as with technical and human resources adequate for emergency management of bearers of acute myocardial infarcts; 5) periodically awarding official certificates of quality to emergency units; 6) disseminating notices about the importance of adopting a philosophy of prioritization of the attention to be given to patients complaining of thoracic pain ${ }^{15}$; 7) establishing central agencies to support decisions (ongoing); 8) setting up of an official course for training in first aid of patients with acute myocardial infarction; 9) establishing a permanent commission to study, discuss, amplify, divulge, and supervise the implementation of these and other measures that may result in the improvement of conditions for the emergency treatment of acute myocardial infarct patients; 10) raising funds for the financing of the measures proposed by partnerships with local entrepreneurs sensitized to participating in a project that is highly relevant for the population of the city of Rio de Janeiro (ongoing).

The study concludes that: 1) a low probability exists that thrombolytic therapy will be performed in the majority of the emergency units both public and private in the city of Rio de Janeiro; 2) a lack of awareness also exists on part of physicians about the importance of the use of acetylsalicylic acid in patients with acute myocardial infarcts; 3 ) a large number $(45.9 \%)$ of the public emergency wards do not have conditions considered minimal for the attendance of patients with acute myocardial infarction; 4) the high degree of credibility granted the SBC/RJ by directors of emergency units as well as by physicians on-call should enable the Society to lead programs of continued medical education, initiating a general change in mentality relative to the use of thrombolytic therapy.

Final comments - This study is not intended to be taken as a definitive report about the quality of the care offered to acute myocardial infarct patients in the emergency units of Rio de Janeiro. Our major objective in planning it was to arouse attention to the already known deficiencies of public emergency assistance available to the population of the lower economic classes of this city, planting a seed from which a partnership between the SBC/RJ, CREMERJ,

\begin{tabular}{|c|c|c|c|c|c|c|c|c|c|c|c|c|}
\hline \multicolumn{13}{|c|}{$\begin{array}{c}\text { Table IV - In the interviews with physicians on-call, the following situation was presented: "you have just attended in this emergency unit a } 40 \text {-year-old } \\
\text { patient with precordial pain that began less than } 1 \mathrm{~h} \text { ago. The electrocardiogram is typical for extensive acute anterior infarction. Transfer to a coronary } \\
\text { or an intensive care unit will only be possible within } 60 \mathrm{~min} \text {. Which drugs would you initiate while waiting for the transfer of the patient?" The majority } \\
\text { of the physicians on-call interviewed did not mention acetylsalicylic acid (AAS). }\end{array}$} \\
\hline \multirow[t]{3}{*}{ In answering: } & \multicolumn{3}{|c|}{ Total } & & \multicolumn{4}{|c|}{ Public } & \multicolumn{4}{|c|}{ Private } \\
\hline & \multicolumn{2}{|c|}{ Yes } & \multicolumn{2}{|c|}{ No } & \multicolumn{2}{|c|}{ Yes } & \multicolumn{2}{|c|}{ No } & \multicolumn{2}{|c|}{ Yes } & \multicolumn{2}{|c|}{ No } \\
\hline & № & $\%$ & № & $\%$ & № & $\%$ & № & $\%$ & № & $\%$ & № & $\%$ \\
\hline Cited AAS? & 20 & 39.2 & 31 & 60.8 & 8 & 38.0 & 13 & 62.0 & 12 & 40.0 & 18 & 60.0 \\
\hline
\end{tabular}


Table V - Interviews with on-call doctors. "Would the idea of the Brazilian Society of Cardiology/RJ promoting updating talks on management of cardiology emergencies and precordial pain in this unit be well received by you "?

\begin{tabular}{|ccc|}
\hline Answers & No. of physicians & $\%$ \\
\hline Yes & 97 & $100 \%$ \\
No & 0 & $0 \%$ \\
& 97 & $100 \%$ \\
\hline
\end{tabular}

and public health authorities might emerge. This would give life to a consistent project aimed at modifying, in the not too distant future, this worrisome situation by more favorable statistical data, capable of further raising the reputation of cardiology in Rio de Janeiro. It would also serve as an example to some other major Brazilian cities like Porto Alegre and São Paulo, which present similar pictures (fig. 2). Simple measures like programs for continued medical education as well as greater and better use of the few existing resources giving emergency units means for at least minimal case attendance will, within a short period, provide solutions for this serious problem.

\section{Acknowledgements}

To the University of the State of Rio de Janeiro, in the person of Professor Dr. Francisco Manes Albanesi $F^{o}$. To the Society of Cardiology of the State of Rio de Janeiro in the person of Dr. Denílson Campos de Albuquerque (President, 1996-1998). To the Technical Chamber of Cardiology of the Regional Council of Medicine in the person of Dr. Cantídio Drummond Netto. To the participants of the Study: Adriana Casaes Passos, Adriana de Oliveira
Campos, Adriana José Soares, Andréia Cristina de Oliveira Frade, Carlos José Rodrigues Coelho, Danielle Zaher Deseta, Fabio de Souza Paolino, Fernanda Barbosa de Almeida Sampaio, Francisco Carlos Lourenço Jr, Isabela Di Puglia de Magalhães Carvalho, João Luiz Fernandes Petriz, Leoni da Silva Carvalho, Luiz Gustavo Teixeira Pinto, Maria Elizabeth Ferreira, Martha Valéria Tavares Pinheiro, Patrícia Elizabeth de Sá Finni, Renato Marano Rocha, Rose Filgueiras, Vanessa Henriques Carvalho, Jamila Costa Ribeiro e Walter Homen Jr.

To the 46 head physicians and 51 on-call physicians of the emergency units, who collaborated with this Study, by supplying valuable information: Hospital Hospital do Andaraí, Hospital Salgado $F^{\circ}$, Hospital Carmela Dutra, Hospital Carlos Chagas, Hospital Albert Schweitzer, PAM Del Castilho, PAM Irajá, PAM Madureira, Hospital Prontocor Tijuca, Hospital Tijucor, Hospital Evangélico, Casa de Saúde Brasil Portugal, Hospital São Vicente de Paula, Hospital Souza Aguiar, Hospital dos Servidores do Estado, Hospital Central do IASERJ, Hospital de Bonsucesso, Hospital Getúlio Vargas, Hospital Paulino Werneck, Hospital Santa Maria Madalena, Hospital Centrocor, Hospital Procor, Hospital Silvestre, Hospital IV Centenário, PAM Ramos, PAM Penha, Hospital Cardoso Fontes, Hospital Lourenço Jorge, Clínica São Bernardo, Hospital Cardiobarra, Hospital Rio Mar, Hospital Riocor, Hospital de Clínicas de Jacarepaguá, Clínica Três Rios, Hospital Renaud Lambert, Hospital Barra D’Or, Hospital Miguel Couto, Hospital Rocha Maia, Hospital da Lagoa, Hospital de Cardiologia de Laranjeiras, Hospital Rocha Faria, Hospital Pedro II, Hospital Pró-Cardíaco, Clínica São Vicente da Gávea, Hospital Prontocor Lagoa, Hospital São Lucas and Hospital Galeão of Braziliam Air Force (Pilot study)

\section{References}

1. Day HW. An intensive coronary care area. Dis Chest 1963; 44: 423-7.

2. Gruppo Italiano per lo Studio della Streptochinasi Nell' Infarto Miocardico (GISSI). Effetiveness of intravenous thrombolytic treatment in acute myocardial infarction. Lancet 1986; i: 397-402.

3. Sharkey SW, Bruneete DD, Ruiz E, et al. An analysis of time delays proceding thrombolysis for acute myocardial infarction. JAMA 1989; 262: 3171-4.

4. Ornato JP. Role of the emergency department in decreasing the time to thrombolytic therapy in acute myocardial infarction. Clin Cardiol 1990; 5(suppl V): V48V52.

5. Birkhead JS. Time delays in provision of thrombolytic treatment in six district hospitals. Joint Audit Committee of Royal College of Physicians of London. Br Med J 1992; 305: 445-8.

6. Gonzalez ER, Jones LA, Ornato JP, et al. Hospital delays and problems with thrombolytic administration in patients receiving thrombolytic therapy: a multicenter prospective assessment. Virginia Thrombolytic Study Group. Ann Emerg Med 1992; 21: 1215-21.

7. Cummings P. Improving the time to thrombolytic therapy for myocardial infarction by using a quality assurance audit. Ann Emerg Med 1992; 21: 1107-10.

8. PorterG, Doughty R, Gamble G, Sharpe N. Thrombolysis in acute myocardial infarction: reducing in hospital treatment delay. N Z Med J 1995; 108: 253-4.
9. Letovsky E, Allen T. Initiating thrombolytic therapy for acute myocardial infarction: Whose job is it anyway? Can Med Assoc J 1996; 154: 509-11.

10. National Heart Attack Alert Program (NHAAP) Coordinating Comittee $60 \mathrm{Mi}$ nutes to Treatment Working Group. U.S. Department of Health and Human Services, Public Health Services, National Institutes of Health, National Heart, Lung and Blood Institute. NIH Publication 1993; 3278.

11. Brasileiro ALS, Paris DS, Ramalho HP. A sub-utilização da terapia trombolítica na cidade do Rio de Janeiro. Buscando as causas. Revista da SOCERJ 1996; 9 : $171-7$

12. Xavier SS. Trombólise primária na rede pública. Experiência inicial do Projeto piloto de ampliação do uso de trombolítico no infarto agudo do miocárdio. Revista da SOCERJ 1997; 10(supl A): 7.

13. Lotufo PA. Mortalidade precoce por doenças do coração no Brasil. Comparação com outros países. Arq Bras Cardiol 1998; 70: 321-5.

14. Lolio CA, Lotufo PA, Lira AC,Zanetta DMT, MassadE. Tendência da mortalidade por doença isquêmica do coração nas capitais de regiões metropolitanas do Brasil, 1979-89. Arq Bras Cardiol 1995; 64: 213-6.

15. Bahr R Growth. Chest Pain Emergency Departments through out United States: cardiologists spin on solving the heart attack problem. Coron Art Dis 1995; 6: 827-30 